\title{
Plurihormonal Pituitary Gland Adenoma
}

National Cancer Institute

\section{Source}

National Cancer Institute. Plurihormonal Pituitary Gland Adenoma. NCI Thesaurus. Code C45916.

An infrequent chromophobic or slightly eosinophilic pituitary gland adenoma that shows immunoreactivity for more than one pituitary hormone, excluding the following two combinations: growth hormone/prolactin/TSH, and FSH/LH. 